\title{
IMPLANTAÇÃO DA TEORIA DAS RESTRIÇÕES (TOC) ATRAVÉS DA ÁRVORE DE REALIDADE ATUAL (ARA): Estudo de Caso em uma Unidade Fabril da Indústria Metalúrgica
}

\author{
Rodrigo Javier Sólla López* \\ Dirceu Grasel ${ }^{\bullet}$
}

Resumo: Este é um estudo de caso de uma unidade fabril da indústria metalúrgica que se vê obrigada a adotar estratégias de redução de custos e de diferenciação de forma simultânea, devido a um cenário de aumento de concorrência no âmbito global. A diminuição da participação no mercado e de seus resultados financeiros provocou um aumento do índice de rejeição de qualidade interna a níveis superiores a $50 \%$. Com sua limitação de recursos humanos e financeiros, a empresa $\mathrm{X}$ está mergulhada em inúmeros problemas e necessita de alguma forma mapeá-los e elaborar um plano de implementação que a leve a maximizar seus resultados a curto e médio prazos. O trabalho propõe-se em primeiro lugar a realizar um Diagnóstico da Situação Atual através da utilização de uma ferramenta denominada Current Reality Tree ou Árvore de Realidade Atual (ARA) provinda dos Processos de Raciocínio (PR's) da Theory of Constrains (TOC) ou Teoria das Restrições. Num segundo momento, a elaborar um plano de implementação que priorize a tratativa dos Efeitos Indesejáveis (EI's), o que levará a empresa X a obter um aumento de competitividade. O trabalho além do Diagnóstico da Situação Atual através da ARA e da realização de um Plano de Implementação, logrou o fortalecimento de uma cultura de melhoria contínua dos processos dentro da companhia, que deve se perpetuar para fazer frente a futuros desafios necessários para o constante aumento de competitividade exigidos pelas forças de mercado para a empresa $X$.

Palavras-chave: Competitividade, Estratégia de Produção, Teoria das Restrições, Árvore de Realidade Atual.

\begin{abstract}
This is a case study of a plant of the metallurgical industry that was forced to adopt a cost reduction and differentiation strategies simultaneously, due to a globally competition increase scenario. The decrease in market share and financial results caused an increase in the internal quality rejection rate to levels above $50 \%$. With its limited human and financial resources, the company $\mathrm{X}$ is steeped in numerous problems and need to somehow map them and draw up an implementation plan that leads to maximize its results in the short and medium term. The study aims firstly to carry out a diagnosis of Current Situation by using a tool called Current Reality Tree (CRT) stemmed from the Thinking Processes (TP) of the Theory of Constraints (TOC). Secondly, to draw up an implementation plan that prioritizes the dealings of Undesirable Effects (UDEs), which will lead the company $\mathrm{X}$ to get an increase of competitiveness. The present work beyond the Diagnosis of Current Situation by the CRT and the realization of an Implementation Plan, has achieved a fortification of a continuous improvement culture processes within the company, which must be perpetuated to face future challenges necessary for the constant increase of competitiveness demanded by the market strengths to the company X.
\end{abstract}

Keywords: Competitiveness, Production Strategy, Theory of Constraints, Current Reality Tree.

\footnotetext{
* Economista formado pela Faculdade de Economia da Universidade Federal de Mato Grosso.

- Professor Titular do programa de Pós-Graduação da Faculdade de Economia da Universidade

Federal de Mato Grosso (UFMT, Cuiabá, MT). Mestre e Doutor em Engenharia de Produção/UFSC.
} 


\section{INTRODUÇÃO}

O aumento de concorrência no âmbito global tem desafiado as empresas de todas as indústrias a buscarem aumento de competitividade. Esse fenômeno força as unidades produtoras a redesenharem suas estratégias de disputa, analisando os cenários externos e internos em busca de vantagens que às levem a um aumento de competitividade e a obterem ganhos de mercado.

De acordo com Porter (2004, p. 36), pode-se definir estratégia competitiva como sendo um conjunto de "ações ofensivas ou defensivas para criar uma posição defensável em uma indústria, para enfrentar com sucesso as cinco forças competitivas e, assim, obter um retorno sobre o investimento maior para a empresa".

Indústria é um grupo de empresas fabricantes de produtos que são substitutos bastante próximos entre si. Existem 5 forças competitivas básicas que determinam o grau de concorrência de uma indústria, são elas: entrada, ameaça de substituição, poder de negociação dos compradores, poder de negociação dos fornecedores e rivalidade entre os atuais concorrentes (PORTER, 2004).

Desta forma, a concorrência em uma indústria não está limitada aos participantes estabelecidos. Clientes, fornecedores, novos entrantes e substitutos influenciam nas relações do mercado e consequentemente nas decisões tomadas pelas unidades produtoras.

Uma vez identificadas as forças que afetam a concorrência em uma indústria, a empresa está em condições de identificar seus pontos fortes e fracos em relação à indústria e com isso adotar as estratégias que entender adequadas para se posicionar de modo a ser mais competitiva e obter vantagens (PORTER, 2004).

Ainda segundo o autor, podem ser elencadas três estratégias genéricas, que podem ser utilizadas simultaneamente, para criar essa posição defensável que permita a superação dos concorrentes de uma indústria. Resumidamente, são elas:

1) Liderança no custo total: quando o custo baixo em relação aos concorrentes torna-se o tema central da estratégia, embora qualidade não possa ser ignorada.

2) Diferenciação: diferenciar o produto ou o serviço oferecido pela empresa, criando algo que seja considerado único no âmbito de toda a indústria. Tal estratégia não permite ignorar os custos, mas não são o alvo estratégico principal. 
3) Enfoque: enfocar um determinado grupo de consumidores, um segmento da gama de produtos oferecidos ou uma área geográfica. A empresa logra atender essas particularidades de forma mais eficaz ou eficiente em relação à concorrência. Tal estratégia não busca liderança de custo ou diferenciação em relação ao mercado como todo, porém naquele nicho específico ela atinge uma ou ambas as posições.

Todas as decisões estratégicas e de comportamento dos agentes de mercado, tanto internos como externos afetam seguramente as características de Produção de uma unidade fabril.

Desde o período pós-guerra, a Produção foi considerada muitas vezes, principalmente no mundo ocidental, como um "mal necessário". Os outros setores normalmente enxergavam a fábrica somente como a principal origem de seus problemas. Em consequência disso, as áreas de manufatura passaram anos sendo excluídas do processo estratégico decisório e sendo somente comunicadas a respeito das decisões já tomadas (CORRÊA; GIANESI, 1996).

Este panorama vem se alterando e o processo decisório da Estratégia de Manufatura vem sendo revalorizado. Segundo Fine e Hax (2014, p. 71), “a operação de Manufatura é o componente empresarial de maior amplitude e complexidade, e o mais difícil de ser administrado". Sua estratégia "afeta e é afetada por muitos grupos organizacionais de dentro e de fora da empresa".

Essa revalorização, se dá principalmente por três razões: A crescente pressão por competitividade, com a queda de importantes barreiras alfandegárias e protecionistas e o surgimento de novos competidores; $\mathrm{O}$ crescente potencial competitivo que representa o recente desenvolvimento de novas tecnologias de processo e gestão da manufatura, e; O melhor entendimento do papel estratégico da produção (CORRÊA; GIANESI, 1996).

O Japão é um grande exemplo de nação que desenvolveu técnicas de gestão da produção que desafiaram países de indústrias mais tradicionais como Inglaterra e Estados Unidos. Grande parte das principais inovações tecnológicas e de gestão de manufatura surgiram no mercado automobilístico no pós-guerra e, posteriormente, as técnicas foram seguidas por outros mercados em que o país se destacou, como eletrodomésticos, aparelhos de som, e câmeras fotográficas (CORRÊA; GIANESI, 1996).

Tal abordagem pioneira na indústria automobilística, que propunha fazer cada vez mais com cada vez menos e aproximar-se a oferecer aos clientes aquilo que eles realmente desejam, é conhecida como produção enxuta (Lean Production) ou TPS 
(Toyota Production System), foi desenvolvida e adotada pala Toyota após a Segunda Guerra Mundial (WOMACK; JONES, 2004). Esses autores afirmam que conheceram muitos gerentes que se afogaram nas técnicas ao tentar implementar partes isoladas de um sistema enxuto sem entender o todo.

A revalorização da estratégia de Manufatura que se dá em detrimento do aumento das pressões competitivas, além das inovações da fabricação enxuta, trouxe também outras ferramentas, metodologias e tecnologias de gestão da produção, destacando-se principalmente: Just in Time (JIT), Material Requirements Planning (MRP) e Optimized Production System (OPT).

Este último (OPT) foi um sistema que deu origem à Teoria das Restrições ou Theory of Constraints (TOC). O gerenciamento das restrições aborda o planejamento, controle de produção de produtos e evoluiu para um conjunto de ferramentas e Processos de Raciocínio (PR's) aplicáveis em qualquer tipo de organização.

São Critérios Competitivos da Manufatura: Qualidade, Custos, Velocidade de Entrega, Confiabilidade de Prazos, Flexibilidade. Conforme o Produto ou Mercado, esses critérios podem ser na visão do consumidor, Critérios Qualificadores e Ganhadores de Pedido (CORRÊA; GIANESI, 1996).

Os Critérios Ganhadores de Pedido "são aqueles considerados pelos clientes como razões-chaves para comprar o produto ou serviço. Aumentar o desempenho em um critério ganhador de pedidos resulta em mais pedidos ou melhora a probabilidade de ganhar mais pedidos". Já os Critérios Qualificadores, "são aspectos da competitividade nos quais o desempenho da produção deve estar acima de um nível determinado, para pelo menos ser considerada pelo cliente" (SLACK, 2008, p. 94).

Segundo ARAÚJO (2004, p. 2), "recursos e esforços consideráveis têm sido investidos pelas organizações no intuito de promover a melhoria contínua de seus processos de manufatura, objetivando o alcance de vantagem competitiva frente ao mercado".

Inserida em um cenário de aumento de concorrência a nível global e tendo identificado redução da participação no mercado e de seus resultados financeiros, a empresa X, se vê obrigada a adotar estratégias de redução de custos e de diferenciação de forma simultânea.

Dada a crescente e acentuada queda na participação de mercado de exportação, identificou-se que a qualidade do produto final deveria melhorar tanto nos quesitos 
funcionais quanto visuais. A empresa decidiu elevar o nível de exigência da qualidade interna dos produtos atuais para assim melhor satisfazer seus consumidores.

De acordo com dados internos da companhia, o impacto imediato dessa medida elevou os níveis de rejeição de qualidade interna (após a montagem final do produto), para mais de $50 \%$.

Slack (2002, apud Araújo, 2004 p. 2) afirma que "a maior parte do tempo da manufatura é despendido na luta contra o fogo dos muitos problemas inesperados que estão sempre ameaçando e debilitando as metas de desempenho".

A empresa $X$ se viu também submergida em inúmeros problemas de produção e qualidade e, dada a limitação de seus recursos tanto humanos quanto financeiros, necessita adotar uma metodologia que, além de identificar os problemas e suas causas, permita classificá-los e priorizá-los, para dedicar foco e concentração da sua estrutura às ações de melhoria que irão maximizar seus benefícios no curto e médio prazo.

Desta forma a empresa $\mathrm{X}$ deve se organizar para atender os quesitos qualificadores e ganhadores de pedido, o que leva aos seguintes questionamentos:

$\mathrm{O}$ que a empresa $\mathrm{X}$ deve fazer para melhorar rapidamente a qualidade de seus produtos e a produtividade fabril?

Como a empresa X pode adotar um critério de priorização de análise e solução de problemas a fim de maximizar os resultados a curto e médio prazo?

Diante destes questionamentos, o estudo realizou um diagnóstico da situação atual da empresa X para permitir que a estrutura seja capaz de concentrar esforços e recursos na solução dos problemas de forma organizada.

Baseado na situação atual, priorizar os Efeitos Indesejáveis (Problemas) a serem estudados e, como resultado final, elaborar um plano de implementação que conduza aos resultados necessários para o aumento da competitividade, identificando assim projetos de melhoria ou ações e alocando recursos na linha do tempo para execução.

A realização deste trabalho foi de suma importância, uma vez que o mapeamento dos Efeitos Indesejáveis (EI's) e a identificação das interações entre eles através das relações de causa e efeito, servirá de norte para superar a atual dificuldade da empresa $\mathrm{X}$ de se organizar, de modo a priorizar os problemas enquanto ao seu entendimento e sua tratativa, e assim traçar um plano claro de ação para atingir gradativamente uma maior estabilidade do processo produtivo e um consequente aumento de competitividade. 
A realização deste programa e a disseminação dos conceitos da TOC para com os atores envolvidos, também contribuirá para enraizar uma cultura de melhoria contínua na empresa $X$.

\title{
2 REFERENCIAL TEÓRICO
}

\subsection{Teoria das restrições (TOC)}

A Teoria das Restrições ou Theory of Constraints (TOC) foi desenvolvida pelo físico israelense Eliyahu Goldratt na década de 1980. Os conceitos ficaram mundialmente conhecidos após a publicação do livro "A Meta" (GOLDRATT; COX, 2002), escrito em forma de romance fictício, onde se expõe problemas de produção em uma empresa industrial e se narra a sobrevivência da mesma a partir da aplicação dos conceitos básicos da TOC.

A TOC surgiu a partir de um sistema de informação chamado Optimized Production Technology (OPT) que pretendia somente auxiliar o processo de planejamento da produção através da administração de gargalos, porém seu espectro foi ampliado.

De acordo com Ferreira (2007, p. 60):

\begin{abstract}
Optimized Production Technology (OPT), foi posteriormente transformada numa técnica de gestão mais ampla que define os objetivos da companhia como sendo: ganhar dinheiro agora, assim como no futuro, provendo sua própria estrutura para guiar na busca destes objetivos. Neste sentido, os ganhos serão obtidos a partir da administração eficiente de todos os recursos e do conjunto de restrições a que a empresa está submetida.
\end{abstract}

Para se compreender de maneira mais clara de que se trata a Teoria das Restrições, se faz necessário colocar que restrição é qualquer coisa que limita o sistema em atingir maior desempenho em relação à sua meta, podendo a restrição ser ou não física (GOLDRATT; COX, 2002).

O processo decisório da Teoria das Restrições foi descrito em 5 passos:

1. Identificar a(s) restrição(ões) do sistema: este primeiro passo objetiva identificar o que limita o desempenho organizacional, ou seja, o que o está impedindo de alcançar resultados infinitos daquilo que busca.

2. Explorar a(s) restrição(ões) do sistema: o passo seguinte prega a exploração, da melhor maneira possível, da restrição anteriormente identificada. Sem que, neste momento, busque-se grandes investimentos no sentido da eliminação total desta restrição. 
3. Subordinar tudo à decisão anterior: Os demais recursos devem fornecer o necessário, nem mais nem menos, daquilo que a restrição precisa consumir. Dessa forma, evitando-se desperdício de recursos e eventuais perda de ganhos.

4. Elevar a restrição do sistema: é o mesmo que reforçar o elo mais fraco da corrente, aumentando a capacidade de processamento do recurso restritivo.

5. Se, nos passos anteriores, uma restrição for quebrada, voltar ao passo 1: ao reforçar o elo mais fraco, a corrente torna-se mais forte, a restrição foi quebrada. Faz-se necessário reiniciar o processo identificando qual o recurso que está, neste momento, restringindo o sistema. (GOLDRATT; COX, 2002, p. 192)

Segundo Goldratt (2002), quando se tem uma política como restrição deve-se tomar cuidado para não deixar com que a inércia se torne uma restrição do sistema.

Dettmer (1997, apud ARAÚJO 2004, p. 10) afirma que "as ferramentas desenvolvidas para a aplicação da Teoria das Restrições são lógicas por natureza e, quando aplicadas em novas soluções, criam soluções distintas”. Araújo (2004) complementa afirmando que "estas soluções são facilmente transferíveis a outras circunstâncias".

A restrição de um sistema pode também ser classificada entre restrições físicas, que seria o caso da limitação da capacidade de produção de uma máquina por exemplo, e restrições não físicas, como características do mercado, produto ou serviço. No caso das restrições não físicas, sua identificação não se dá de forma tão clara e sua quantificação não é de fácil mensurabilidade (ARAÚJO, 2004).

Ainda segundo o autor, "para as restrições não físicas, utiliza-se o Processo de Raciocínio que é composto por ferramentas de análise lógica que dão subsídios para o diagnóstico de problemas, bem como a formulação de soluções e planos de ação para implementá-las" (ARAÚJO, 2004, p. 14).

2.2 Método dos processos de raciocínio

Existem cinco ferramentas do Processo de Raciocínio da TOC, são elas:

Árvore da Realidade Atual (ARA);

Diagrama de Dispersão de Nuvem (DDN);

Árvore da Realidade Futura (ARF);

Árvore de Pré-Requisitos (APR) e 
Árvore de Transição (AT).

Estas ferramentas são capazes de responder a três questões que permeiam qualquer processo de mudança: "O que mudar?", "Para o quê mudar?" e, "Como mudar?" (GOLDRATT, 2004).

A primeira ferramenta associada à questão "O que mudar?", é a Árvore de Realidade Atual (ARA), à qual será dada ênfase no presente trabalho uma vez que será diretamente utilizada no estudo de caso. A ARA parte de dois pressupostos básicos:

O primeiro é que um problema percebido é um "efeito indesejável" (EI), que nada mais é do que a consequência negativa de uma causa raiz. Goldratt (2004), afirma que a grande maioria dos problemas organizacionais são dependentes uns dos outros e que existe entre eles uma forte relação de causa-efeito.

O segundo pressuposto é de que se deve buscar a identificação de poucos elementos responsáveis pela maioria dos Efeitos Indesejáveis. Para Goldratt (2004), apenas um ou dois problemas-cernes são a causa de todos os demais, sendo que os efeitos indesejáveis brotam do problema-cerne.

Estas poucas causas ou "problemas-cernes" são diagnosticados por meio de um diagrama expresso de forma lógica, onde se interligam os Efeitos Indesejáveis existentes, formando assim a ARA. A figura 1 mostra o esquema de Árvore de Realidade Atual. 


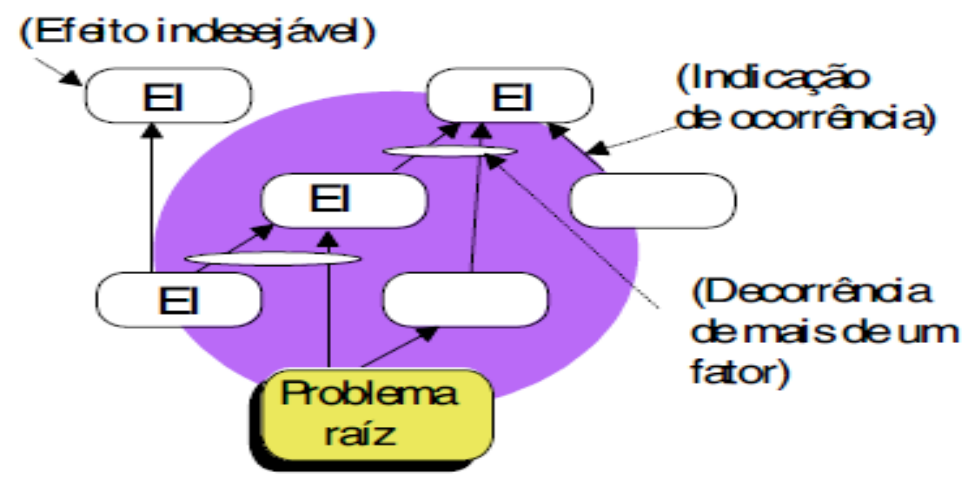

Fonte: RENTES (2000, p. 56)

A Árvore da Realidade Atual baseia-se na relação chave: SE (Causa), ENTÃO (Efeito). A figura 2, demonstra a forma de fazer a leitura da árvore.

\section{FIGURA 2 - ESQUEMA DE INDICAÇÃO DE LEITURA DE UMA ÁRVORE DE} REALIDADE ATUAL

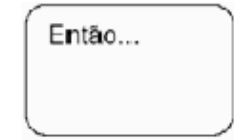

$\mathbf{A}$

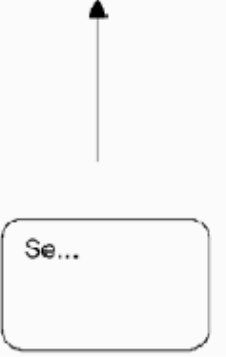

Fonte: ARAÚJO (2004, p. 16)
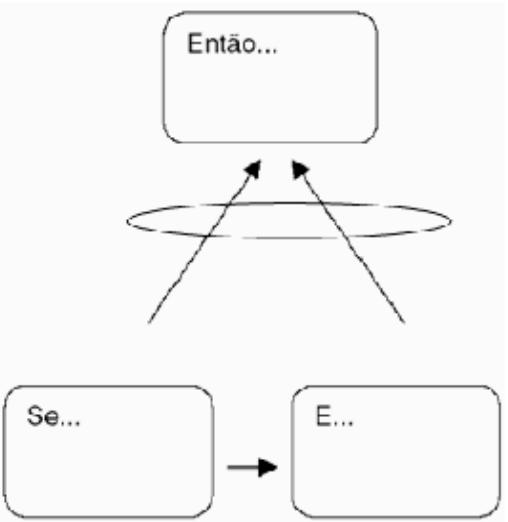
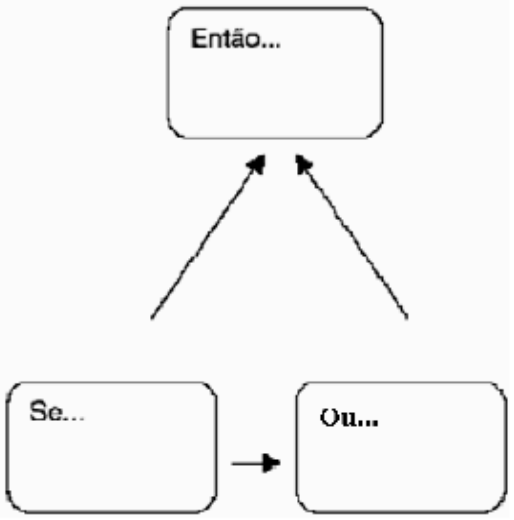

A situação ideal é aquela em que a ARA apresenta apenas uma única causa raiz. Um problema-raiz é identificado como sendo aquele responsável pela grande maioria dos Efeitos Indesejáveis (cerca de 90\%), configurando-se como sendo a restrição do sistema. No entanto, na maioria dos casos, isto não ocorre devido à limitação de conhecimento dos envolvidos, resultando em um conjunto de causas raízes 
independentes que devem ser estudadas com maior profundidade para que futuramente se conheça a causa raiz (ARAÚJO, 2004).

Rentes (2000) apresenta uma proposta para o desenvolvimento da ARA em uma adaptação de Dettmer (1997), apud ARAÚJO (2004). Segue abaixo:

a) Criação de lista de Efeitos Indesejáveis.

- Colete os Efeitos Indesejáveis (EI) levantados.

- Individualize estes efeitos em uma lista EI na forma de afirmações claras. Utilize um post-it para cada afirmação.

- Disponha os EI em um quadro.

b) Inter-relação (um a um) entre os EI.

- Inter-relacione os EI, criando relações de causa e efeito.

- Construa pequenos fragmentos de árvore.

c) Construção da primeira tentativa de Árvore da Realidade Atual (ARA).

- Construa ligações entre os fragmentos (use papel de (flip chart).

- Pense na existência de causas mais profundas, que possam fazer conexões entre os fragmentos.

- Leia a ARA resultante, considerando as Categorias de Reservas Legítimas.

- Adicione mais informações se necessário.

d) Escrutínio de ARA.

- Apresenta a árvore para um grupo de projeto que foi entrevistado durante o Levantamento de Situação.

- Identifique e registre as críticas e observações complementares à realidade apresentada na ARA.

e) Reconstrução da ARA, caso necessário.

- Individualize as novas entidades ou EI em afirmações, incluindo-as na ARA.

- Modifique as relações entre as entidades, caso necessário.

- Questione se a ARA resultante reflete a sua instituição sobre a área.

- Adicione novas entidades se necessário.

- Apresenta a ARA novamente para o grupo de projeto.

f) Identificação das Causas Raízes.

• Examine as "entradas da ARA", isto é, entidades que não têm seta "entrando", só saindo.

- Identifique as causas raízes que apresentam mais contribuições em termos de efeitos indesejáveis. 
Obter a solução dos problemas raízes é o próximo objetivo dos Processos de Raciocínio que através do Diagrama de Dispersão de Nuvem (DDN) e da Árvore de Realidade Futura (ARF), respondem à segunda questão "Para o quê mudar?” (RENTES, 2000).

Para Goldratt (2004), as pessoas dentro de uma empresa têm intuição suficiente para reconhecerem a existência de um problema-raiz e somente a existência de um conflito interno explicaria o fato de tal problema ainda existir ou não ter sido tratado. $\mathrm{O}$ Diagrama de Dispersão de Nuvem é a ferramenta adequada para eliminar tais conflitos. A verbalização desses conflitos não permite negociações e sim a eliminação das razões de sua existência através de uma ideia que a TOC chama de “injeção" (RENTES, 2000).

A partir de então, pode-se partir para a construção da Árvore de Realidade Futura que consiste em mostrar a substituição dos Efeitos Indesejáveis da ARA por Efeitos Desejáveis.

A transição para uma nova realidade é feita através da Árvore de Pré-requisitos (APR), que permite a implantação das injeções anteriormente obtidas, subdividindo o processo de atingimento do objetivo final em objetivos intermediários e da Árvore de Transição (AT), onde se planeja de forma mais detalhada as mudanças graduais necessárias à implantação das injeções na empresa. E com esta últimas duas ferramentas (APR e AT) se responde à última questão “Como mudar?” (RENTES, 2000).

Faz-se vital dizer que o uso dos Processos de Raciocínio não implica necessariamente fazer uso de todas as ferramentas que constituem os Processos de Raciocínio para resolver um determinado problema, ou seja, eles podem ser utilizados seletivamente (RENTES, 2000).

\section{MÉTODO DE PESQUISA}

Este trabalho define-se como um estudo de caso que, segundo Yin (2001, p.32), "é uma inquirição empírica que investiga um fenômeno contemporâneo dentro de um contexto da vida real, quando a fronteira entre o fenômeno e o contexto não é claramente evidente e onde múltiplas fontes de evidência são utilizadas”.

De acordo com Wimmer (1996, p. 161), uma das características do método de estudo de caso é a indução, pois "os princípios e generalizações emergem a partir da 
análise de dados particulares. Em muitas ocasiões, mais que verificar hipóteses formuladas, o estudo pretende descobrir novas relações entre elementos".

Em geral, os estudos de caso são entendidos como de natureza qualitativa na coleta e no tratamento dos dados. Dessa forma, esta aplicação foi realizada na indústria metalúrgica, em duas unidades fabris, com a participação de funcionários que detinham o conhecimento empírico e colaboraram com o pesquisador na identificação e na descoberta de novas relações entre os efeitos indesejáveis do processo produtivo. Essa prática permitiu que fossem aplicadas técnicas e ferramentas do Processo de Raciocínio da TOC, particularmente a ARA para a realização do diagnóstico da situação atual da empresa X.

O motivo da Árvore de Realidade Atual do Processo de Raciocínio ter sido escolhida, já que a ferramenta comumente utilizada para gestão de melhorias, análise de problemas ou busca de causas-raízes é o diagrama de causa-efeito (ou diagrama de Ishikawa ou ainda diagrama espinha de peixe), consiste no fato de que, de acordo com Slack (2008, p. 614), “os diagramas de causa-efeito são um método particularmente efetivo de ajudar a pesquisar as raízes de problemas", porém eles devem ser separados para cada problema e, no atual trabalho o estabelecimento de prioridade enquanto a que problema resolver primeiro é fator crítico de sucesso para a empresa $\mathrm{X}$ maximizar resultados.

Quanto à tipologia, foi realizada pesquisa bibliográfica e de campo. De acordo com Gil (1999, p. 65), “a pesquisa bibliográfica é desenvolvida a partir de material já elaborado, constituído principalmente de livros e artigos científicos”. Martins (2000, p. 28) acrescenta que o objetivo desse tipo de pesquisa é "recolher, selecionar, analisar e interpretar as contribuições teóricas já existentes sobre determinado assunto".

Já os estudos de campo consistem na coleta de dados provenientes da observação ou dados que se obtêm através do levantamento de declarações e respostas de pessoas capazes de fornecer informações úteis aos objetivos da pesquisa (CHIZZOTTI, 2005).

Para realizar o diagnóstico da situação atual da empresa $\mathrm{X}$ e permitir que a estrutura seja capaz de concentrar esforços e recursos na solução dos problemas de forma organizada, foram priorizados os Efeitos Indesejáveis e posteriormente foi elaborado um plano de implementação de ações a serem implementadas para alcançar os resultados desejados.

Assim, este trabalho foi realizado em duas etapas: 
Na primeira, denominada Diagnóstico da Situação Atual, foi utilizada a Árvore de Realidade Atual (ARA), uma vez que por meio dela é possível identificar a causa raiz dos Efeitos Indesejáveis (EI's), bem como as interações entre os mesmos, deixando evidente aquele que deve ser priorizado.

Nesta etapa, inicialmente, em conjunto com a alta estrutura da empresa, definiu-se que a primeira rodada de discussões seria realizada com os gerentes para que, posteriormente, eles indicassem outros funcionários aptos a colaborar. Desses encontros foram surgindo as listas de Efeitos Indesejáveis, totalizando 38 deles, com os quais se elaborou a Árvore de Realidade Atual ao estabelecer a relação de causa-efeito entre eles.

A segunda etapa, chamada de Plano de Implementação, consiste na identificação dos Efeitos Indesejáveis considerados causas-raízes, identificados facilmente já que não são efeito de nenhum outro Efeito Indesejável ou este ainda não é conhecido e, na identificação de Efeitos Indesejáveis considerados causas-raízes intuitivas, já que o grupo envolvido pode chegar ao consenso sobre a prioridade de alguns EI's que ao serem eliminados serão de alto impacto.

Após a identificação dos EI's prioritários para serem eliminados, passa-se à definição das ações necessárias para solucionar os problemas detectados, identificando área de responsabilidade da ação e estimativa de prazo para conclusão.

\section{APLICAÇÃO PRÁTICA: O ESTUdO DE CASO}

Esta aplicação foi realizada envolvendo colaboradores de duas unidades fabris de uma indústria metalúrgica. O presente trabalho foi focado somente em uma família de produtos.

4.1 Apresentação da empresa, sua relevância, características do mercado e da produção

O Brasil é um dos maiores produtores e exportadores do produto em questão. Segundo uma pesquisa sobre o produto, entre 2001 e 2012, o Brasil foi o quarto maior exportador do mundo (atrás somente dos EUA, Itália e Alemanha), com receitas totais de US\$ 2,8 bilhões. No período as exportações cresceram quase 300\% chegando a US\$ 293 milhões em 2012. 
A Empresa X possui aproximadamente 2.000 colaboradores entre mão de obra direta e indireta e é, segundo auto definição, uma das três maiores fabricantes deste produto do mundo. A empresa possui vasta gama de modelos deste produto. Atualmente exporta seus produtos para mais de 70 países.

Segundo dados da empresa, a demanda de Civis faz dos EUA o principal destino do produto desta empresa. A empresa depende massivamente do mercado americano e do Brasil, somente 4,2\% das vendas em 2011 foram para outros países.

E empresa detém praticamente um monopólio no mercado nacional. Atualmente nos EUA, ela tem presença menor, porém relevante. Sua participação neste mercado já atingiu $20 \%$.

A partir de 2013 o desempenho da empresa apresentou um declínio acentuado. No mercado nacional a Empresa teve de enfrentar problemas sérios uma vez que foram detectadas falhas no funcionamento do produto em mais de uma ocasião. Estas falhas também começaram a aparecer no mercado norte americano até que no ano de 2014 dada à dificuldade financeira em que se encontrava, foi adquirida por outro grupo.

Em face aos notórios problemas de qualidade, a empresa decide por tornar mais rigoroso o sistema de controle de qualidade interno, o que a levou a alcançar níveis de rejeição após a montagem final superiores a 50\%.

Neste cenário de indefinições e de caos do ambiente fabril é que este trabalho foi realizado. Após uma análise mercadológica realizada pela própria empresa, os quesitos qualificadores e ganhadores de pedido foram definidos conforme abaixo.

Quesitos Qualificadores: Foram definidos como quesitos qualificadores, alguns aspectos funcionais do produto como a ausência de riscos à segurança do usuário.

Quesitos Ganhadores de Pedido: Foram definidos como quesitos ganhadores de pedido, o custo, e os aspectos visuais do produto, que são a ausência de riscos, batidas e marcas nos locais de fácil visualização e manuseio por parte do usuário.

Busca-se, portanto, com este trabalho definir um plano de ação baseado num diagnóstico da Situação Atual, para que a empresa volte a atender os quesitos qualificadores e ganhadores de pedido e consequentemente volte a ter resultados financeiros positivos. A seguir, apresenta-se o processo de desenvolvimento do Diagnóstico da Situação Atual. 


\subsection{Diagnóstico da situação atual}

De acordo com o método proposto, o Diagnóstico da Situação Atual da produção foi realizado através da construção da Árvore de Realidade Atual (ARA).

Para desenvolvê-la, primeiramente contou-se com ajuda da alta estrutura da empresa para escolher quais colaboradores fariam parte da formação do grupo de trabalho que iria discutir e debater os problemas da empresa a fim de chegarem a um consenso quanto à relação de causa e efeito entre eles.

Num primeiro momento, procurou-se um perfil de colaboradores com nível de Gerência, dada a delicadeza dos assuntos a serem abordados e a necessidade de se juntar simultaneamente conhecimentos técnicos e de gestão e, de conhecer com certo nível de detalhes o histórico da companhia e seus principais desafios.

Deste encontro inicial podem se destacar alguns Efeitos Indesejáveis que serviram de ponto de partida para os primeiros exercícios de raciocínio:

$\rightarrow$ Alto Índice de Rejeição/Não conformidades após a montagem final do produto;

$\rightarrow$ Baixo volume expedido;

$\rightarrow$ Alto índice de Absenteísmo nas Linhas de Montagem;

$\rightarrow$ Defeitos encontrados em produtos acabados e vendidos;

$\rightarrow$ Earnings Before Interests, Taxes, Depreciation and Amortization (EBITDA ${ }^{1}$ ) da Empresa é negativo;

$\rightarrow$ Critérios de qualidade se tornaram mais rigorosos.

Após o primeiro encontro com os Gerentes onde se apresentou a metodologia proposta, foi permitida e incentivada a participação de colaboradores que os Gerentes entendessem necessária ou relevante para o esclarecimento e detalhamento dos Efeitos Indesejáveis listados e suas correlações. Os encontros passaram a ser diários e foram também complementados através de entrevistas individuais a diferentes atores a fim de enriquecer a lista de Efeitos Indesejáveis.

Alguns dos Efeitos Indesejáveis foram descobertos ou colocados a partir de investigações ou relatórios de estudos minuciosos que foram acontecendo ao longo do processo de construção da Árvore.

O conjunto de todos os Efeitos Indesejáveis mapeados na Árvore de Realidade Atual, passaram a ser enumerados conforme quadro 1:

\footnotetext{
${ }^{1}$ EBITDA é a geração de caixa consolidada, medida pelos lucros antes dos juros, impostos, depreciação e amortização.
} 


\section{Quadro 1 - EFEITOS INDESEJÁVEIS}

\begin{tabular}{|c|c|}
\hline Número & Efeito Indesejável \\
\hline 010 & Alto Índice de Rejeição/Não conformidades após a montagem final do produto \\
\hline 020 & Baixo volume expedido \\
\hline 030 & Alto índice de Absenteísmo nas Linhas de Montagem \\
\hline 040 & Defeitos encontrados em produtos acabados e vendidos \\
\hline 050 & EBITDA da Empresa é negativo \\
\hline 060 & Critérios de qualidade se tornaram mais rigorosos \\
\hline 070 & Existe uma despadronização de critérios de qualidade \\
\hline 080 & Defeitos Visuais \\
\hline 090 & Defeitos Funcionais \\
\hline 100 & Sistema de controle de qualidade é falho \\
\hline 110 & Existe pressão interna excessiva para que o volume de produção seja expedido \\
\hline 120 & Alto custo de produção \\
\hline 130 & Perda de competitividade \\
\hline 140 & Redução da fatia de mercado \\
\hline 150 & Funcionários desmotivados \\
\hline 160 & Plano de carreira inadequado \\
\hline 170 & Treinamento de colaboradores é insuficiente \\
\hline 180 & $\begin{array}{l}\text { Existe falta de abastecimento no tempo correto de componentes internos e } \\
\text { externos }\end{array}$ \\
\hline 190 & Ausência de mecanismo eficiente de programação diária \\
\hline 200 & Baixa aderência à programação \\
\hline 210 & Alta variação no processo produtivo \\
\hline 220 & Qualidade dos produtos é questionável \\
\hline 230 & Não atendimento de quesitos qualificadores e ganhadores de pedido \\
\hline 240 & Excesso de retrabalhos e ajustes durante o processo de montagem \\
\hline 250 & Despadronização do método de montagem \\
\hline 260 & Peças necessitam ser ajustadas para o correto funcionamento do produto \\
\hline 270 & $\begin{array}{l}\text { Os ajustes e retrabalhos exigem, dentre outros movimentos desnecessários, } \\
\text { batidas de martelo nos } \\
\text { produtos. }\end{array}$ \\
\hline 280 & Problemas de Ergonomia \\
\hline 290 & Excesso de Manuseio durante o processo produtivo \\
\hline 300 & Condição de Banca de montagem inadequada \\
\hline 310 & Alguns Critérios de Qualidade não ficaram claros \\
\hline 320 & Desenvolvimento de Produtos não cumpre todas as suas etapas antes da \\
\hline
\end{tabular}




\begin{tabular}{|l|l|}
\hline & comercialização. \\
\hline 330 & $\begin{array}{l}\text { Maquinário atual não tem capacidade para produção com alta precisão no volume } \\
\text { e velocidade necessários }\end{array}$ \\
\hline 340 & Peças não são intercambiáveis \\
\hline 350 & $\begin{array}{l}\text { Redução das faixas de especificação das cotas críticas dos componentes exigem } \\
\text { maquinário mais avançado }\end{array}$ \\
\hline 360 & Condições de armazenamento inadequadas \\
\hline 370 & Concepção do Projeto do produto prevê ajustes na montagem final \\
\hline 380 & $\begin{array}{l}\text { As faixas de especificação das cotas críticas dos componentes não garantem a } \\
\text { intercambiabilidade das peças }\end{array}$ \\
\hline
\end{tabular}

Fonte: Elaborada pelos autores

Alguns dos Itens listados acima foi somente identificado já durante a montagem da Árvore de Realidade Atual. A medida que o raciocínio vai ligando os Efeitos Indesejáveis é natural que vão surgindo outros EI's complementares. A ARA pode ser apreciada na figura 3 . 
FIGURA 3 - ÁRVORE DE REALIDADE ATUAL

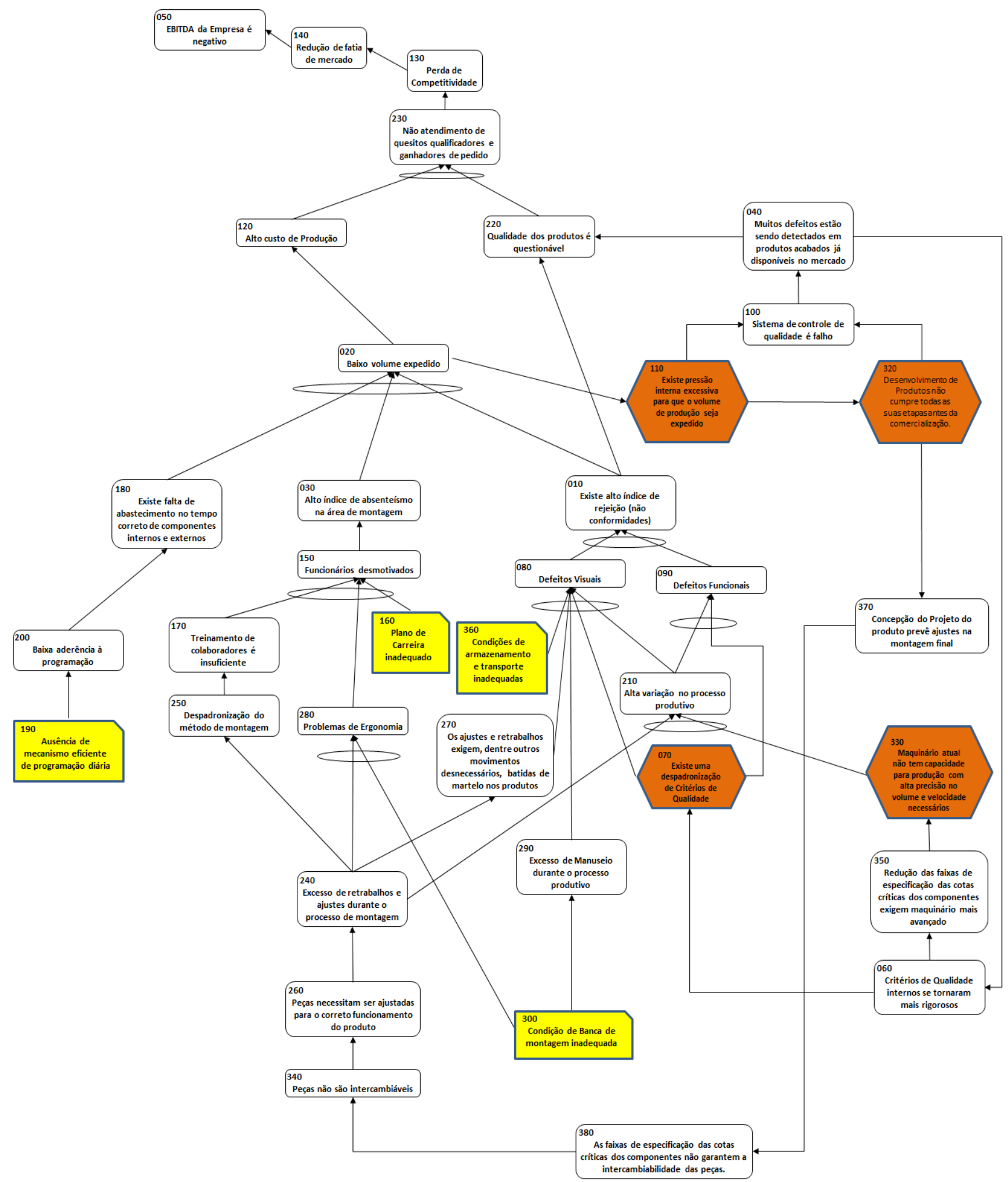

Fonte: Elaborada pelos autores

Amarelo =

Laranja
Efeitos indesejáveis causas raízes;

Efeitos indesejáveis causas raízes intuitivas; 
Abaixo segue a leitura da Árvore de Realidade Atual:

Se existe um alto índice de Rejeição ou não conformidade de 50\% após a montagem final dos produtos (010), então temos um baixo volume expedido (020). Por consequência do baixo volume expedido (020) existe uma pressão interna excessiva para que o volume expedido aumente (110).

Esse ambiente faz com que o sistema de qualidade sofra pressões e se torne mais suscetível a falhas (100). Se o sistema de qualidade é falho (100), então muitos defeitos acabam sendo detectados em produtos acabados já comercializados (040), o que faz com que de modo geral a qualidade dos produtos seja questionável (220). Ao mesmo tempo, se há um baixo volume expedido (020), se elevam os custos de produção (120) e somados à baixa qualidade (220), os quesitos qualificadores e ganhadores de pedido não são atendidos (230).

Se os quesitos ganhadores de pedido e qualificadores não são atendidos (230), configura-se uma perda de competitividade (130), que tem por consequência uma redução da fatia de mercado (140) e reflete-se no EBITDA da Empresa que se encontra negativo (050).

Até então este momento, se tinha como principal causa raiz ao baixo volume expedido (20), simplesmente o alto índice de rejeição (010). Porém com a ausência de um mecanismo eficiente de programação diária (190), têm-se uma baixa aderência à programação (200), então existe uma falta de abastecimento no tempo correto dos componentes internos e externos (180), o que também contribui para um baixo volume expedido (020).

Outra consequência dos defeitos encontrados após a venda dos produtos (040), é que o sistema de qualidade reagiu fazendo naturalmente com que os critérios de qualidade internos se tornassem mais rigorosos (060), então houve uma despadronização dos critérios de qualidade (070), o que aumenta ainda mais a quantidade de defeitos funcionais (090) e defeitos visuais (080), contribuindo para o alto índice de rejeição (010).

Outro aspecto importante levantado pela equipe foi a má condição das bancas de montagem (300). Esse problema gera no mínimo quatro Efeitos Indesejáveis diretos. A condição da banca de montagem (300), causa uma despadronização do método de montagem (250), e evidencia que o treinamento dos colaboradores é ineficiente (170). 
Ao mesmo tempo a má condição das bancas (300) provocam problemas de ergonomia. Somando os treinamentos insuficientes (170), aos problemas de ergonomia (280) e a um plano de carreira inadequado (160), então têm-se funcionários da área de montagem desmotivados (150), ao ponto de terem um alto índice de absenteísmo (030), o que também contribui diretamente para um baixo volume expedido (20).

Por último têm-se que a má condição da banca de montagem (300) provoca um excesso de manuseio no processo produtivo (290), o que também contribui para incidirem mais defeitos visuais (080). Além desses problemas, os defeitos visuais (80) também são consequência das condições inadequadas de armazenamento e transporte das peças e produtos acabados (360).

Um outro "galho" da ARA a partir do EI que indica o aumento de rigor dos Critérios de Qualidade (060) que é consequência dos defeitos encontrados em campo (040), se descobre quando a redução das faixas de especificação das cotas críticas dos componentes exigem um maquinário mais avançado (350), então o maquinário atual não tem capacidade para produção com alta precisão no volume e velocidade necessários (330), o que também contribui de forma relevante para a alta variação do processo produtivo (210).

Desta forma, a variação do processo (210), tem por consequência o aumento de defeitos visuais (080) e funcionais (090), que contribuem diretamente para o alto índice de rejeição (010) e o baixo volume expedido (020).

A pressão para que o volume seja expedido (110) a todo custo também influencia negativamente na área de desenvolvimento de produtos, fazendo com que ela não cumpra todas as etapas do seu processo de projeto de produto antes de sua comercialização (320).

A partir do estabelecimento desta interligação de causa e consequência se desenha um ciclo vicioso na ARA que também mostrará um dos principais campos de ação para a eliminação da maior quantidade de restrições e Efeitos Indesejáveis neste sistema a médio e longo prazos.

Se o Desenvolvimento de produtos queima etapas para acelerar seu processo (320), significa então que já desde a concepção do produto estão previstos ajustes na montagem (370), uma vez que as faixas de especificação das cotas críticas dos componentes não garantes a intercambiabilidade das peças (380). Conclui-se, portanto, que as peças não são intercambiáveis (340), uma vez que mesmo estando dentro do 
especificado pela engenharia de produto, as peças necessitam ser ajustadas para o correto funcionamento do produto (260).

No momento em que existe essa necessidade de ajuste (260), há um excesso de retrabalhos e ajustes durante o processo de montagem (240), interferindo diretamente na despadronização do método de montagem (250), nos problemas de ergonomia (280), provocando alta variação do processo produtivo (210) e exigindo, dentre outros movimentos desnecessários, batidas com martelos nos produtos já montados (220), o que é fator determinante para a alta quantidade de defeitos visuais (080).

O retorno aos EI's (210) e (080), configuram o Ciclo Vicioso do qual iremos tratar na seção seguinte, identificando quais EI's devem ser priorizados para sofrerem intervenções e assim poder minimizar ou mitigar a maioria dos Efeitos Indesejáveis aqui mapeados.

\subsection{Plano de implementação}

O Plano de Implementação permitirá a visualização clara dos distintos projetos de melhoria a serem implementados, suas ações específicas devidamente classificadas por tipo de problema, área responsável pela implementação e duração da ação.

Desta forma o Plano representará a alocação dos recursos humanos disponíveis de forma organizada e seguindo uma sequência lógica que permitirá gerar o maior impacto positivo no curto, médio e longo prazo, uma vez que priorizará as ações que segundo o entendimento do grupo, dada a limitação de recursos e conhecimento naquele momento, representam as soluções para os Efeitos Indesejáveis considerados causas-raiz.

Para se determinar quais dos Efeitos Indesejáveis serão as prioridades a serem discutidas nos grupos de trabalho, o critério utilizado foi o de escolher as entidades que somente possuem setas "saindo", ou seja, que não foi mapeada nenhuma causa para aquele EI, então ele poderia ser uma causa-raiz.

O quadro 2, mostra as EI's que foram identificados como causas-raízes para os demais EI's. 
QUADRO 2 - EFEITOS INDESEJÁVEIS - CAUSAS - RAÍZES

\begin{tabular}{|l|l|}
\hline Número & \multicolumn{1}{c|}{ Efeito Indesejável } \\
\hline 160 & Plano de carreira inadequado \\
\hline 190 & Ausência de mecanismo eficiente de programação diária \\
\hline 300 & Condição da Banca de Montagem Inadequada \\
\hline 360 & Condições de armazenamento inadequadas \\
\hline
\end{tabular}

Fonte: Elaborada pelos autores

Este primeiro critério adotado determinou as primeiras ações que deveriam ser realizadas para que a maior quantidade de Efeitos Indesejáveis desaparecesse. Porém foi consenso do grupo de que haviam outros pontos na ARA que poderiam apresentar mais contribuições em termos de mitigar os problemas, conforme mostra a Quadro 3.

\section{QUADRO 3 - EFEITOS INDESEJÁVEIS - CAUSAS - RAÍZES INTUITIVAS}

\begin{tabular}{|l|l|}
\hline \multicolumn{1}{|c|}{ Número } & \multicolumn{1}{c|}{ Efeito Indesejável } \\
\hline 070 & Existe uma despadronização de critérios de qualidade \\
\hline 110 & Existe pressão interna excessiva para que o volume de produção seja expedido \\
\hline 320 & \begin{tabular}{l} 
Desenvolvimento de Produtos não cumpre todas as suas etapas antes da comercialização. \\
\hline 330
\end{tabular} \\
$\begin{array}{l}\text { Maquinário atual não tem capacidade para produção com alta precisão no volume e } \\
\text { velocidade necessários }\end{array}$ \\
\hline
\end{tabular}

Fonte: Elaborada pelos autores

O quadro 4 mostra as ações ou projetos de melhoria definidos, em ordem de prioridade, para combater de forma organizada e eficaz a maior quantidade de Efeitos Indesejáveis considerados causas-raízes possível dada a limitação de recursos. 


\section{QUADRO 4 - PLANO DE IMPLEMENTAÇÃO DE AÇÕES / PROJETOS DE MELHORIA PARA COMBATER OS EFEITOS INDESEJÁVEIS CONSIDERADOS CAUSAS-RAÍZES}

\begin{tabular}{|c|c|c|c|c|}
\hline $\begin{array}{c}N^{\mathbf{o}} \\
\text { Ação }\end{array}$ & EI & Descrição da Ação ou Projeto de Melhoria & $\begin{array}{c}\text { Área } \\
\text { Responsável }\end{array}$ & $\begin{array}{l}\text { Prazo } \\
\text { (Dias) }\end{array}$ \\
\hline 1 & 110 & $\begin{array}{l}\text { Adequar volume programado à realidade atual da fábrica de } \\
\text { modo a dar foco à qualidade e não ao volume }\end{array}$ & PCP & 15 \\
\hline 2 & 320 & $\begin{array}{l}\text { Parar projetos em andamento e desenvolver um novo projeto } \\
\text { de produto garantindo a substituição do ajuste pela } \\
\text { intercambiabilidade de componentes }\end{array}$ & $\begin{array}{l}\text { Engenharia de } \\
\text { Produto }\end{array}$ & 120 \\
\hline 3 & 330 & $\begin{array}{l}\text { Realizar estudo de Capabilidade das Máquinas de todo o } \\
\text { processo produtivo do produto a fim de se obter um relatório } \\
\text { preciso da real condição do processo atual }\end{array}$ & $\begin{array}{l}\text { Engenharia de } \\
\text { Processo }\end{array}$ & 60 \\
\hline 4 & 330 & $\begin{array}{l}\text { Criar um Comitê de Terceirizações, aonde sejam avaliados } \\
\text { possíveis fornecedores de componentes aos quais } \\
\text { entendamos que não somos capazes de fabricar atualmente } \\
\text { com a qualidade requerida }\end{array}$ & Suprimentos & 7 \\
\hline 5 & 300 & $\begin{array}{l}\text { Realizar projeto de banca de montagem modelo, de acordo } \\
\text { ao Projeto de Produto da ação } n^{\circ} 2\end{array}$ & $\begin{array}{l}\text { Engenharias } \\
\text { de Processo e } \\
\text { Produto }\end{array}$ & 120 \\
\hline 6 & 70 & $\begin{array}{l}\text { Criar um Comitê para discussão de Critérios de Qualidade a } \\
\text { fim de definir, elaborar procedimento, disseminar e treinar } \\
\text { colaboradores da qualidade e da operação }\end{array}$ & Qualidade & 7 \\
\hline 7 & 360 & $\begin{array}{l}\text { Criar projeto de caixas para transporte de componentes e } \\
\text { produtos acabados para transporte ao longo do processo e } \\
\text { transporte externo }\end{array}$ & Logística & 20 \\
\hline 8 & 190 & $\begin{array}{l}\text { Implantar supermercado de componentes na entrada do setor } \\
\text { de montagem }\end{array}$ & $\begin{array}{c}\text { PCP / } \\
\text { Logística }\end{array}$ & 120 \\
\hline 9 & 190 & Criar Comitê para discussão a respeito do Projeto de MRP & $\mathrm{PCP} / \mathrm{TI}$ & 7 \\
\hline 10 & 160 & $\begin{array}{l}\text { Desenvolver plano de carreira para área de montagem } \\
\text { levando em consideração critérios claros de desempenho }\end{array}$ & RH & 30 \\
\hline
\end{tabular}

Fonte: Elaborada pelos autores

\section{CONSIDERAÇÕES FINAIS}

O presente trabalho se limitou a identificar as ações de melhorias após os primeiros ciclos de discussões e consensos dos Grupos de Trabalhos propostos, portanto, não faz parte do escopo a análise da efetividade das ações. 
É importante ressaltar que as decisões tomadas enquanto a prazos e prioridades foram baseadas em um conhecimento limitado dos envolvidos, podendo sofrer alterações à medida que aconteça um aprofundamento do conhecimento dos problemas e suas causas.

Conforme vimos no desenvolvimento do trabalho, algumas ações consistiram na criação de outros subprojetos, por se tratarem de múltiplas ações de longo prazo, que exigem investimentos adicionais.

As ferramentas da TOC se caracterizam por não serem estáticas, e sim dinâmicas. Assim, quanto maior for o conhecimento coletivo dos atores envolvidos na organização a respeito da natureza dos Efeitos Indesejáveis e a interação entre eles, mais fidedigno será o retrato da realidade e maior será a efetividade das ações.

Destaca-se como principal consequência positiva da implantação desta metodologia, além dos resultados objetivos das ações definidas, o fortalecimento de uma cultura de Melhoria Contínua dos processos. Tal fortalecimento foi possível somente através de um claro critério de priorização, que deve se perpetuar para fazer frente a desafios futuros, necessários para o constante aumento de competitividade exigido na Empresa $\mathrm{X}$.

\section{REFERÊNCIAS}

ARAÚJO, C. A. C. Desenvolvimento e aplicação de um método para implementação de sistemas de produção enxuta utilizando os processos de raciocínio da teoria das restrições e o mapeamento do fluxo de valor. Dissertação (Mestrado) Escola de Engenharia de São Carlos, Universidade de São Paulo, São Carlos, 2004.

CHIZZOTTI, A. Pesquisa em ciências humanas e sociais. São Paulo:Cortez, 2005.

CORRÊA G.; GIANESI L. Just In Time, MRP II e OPT - Um enfoque estratégico. São Paulo: Atlas, 1996.

FERREIRA, A. H. Aspectos importantes na implantação da teoria das restrições na gestão da produção: um estudo multicaso. Dissertação (Mestrado) Faculdade de Economia, Administração e Contabilidade de Ribeirão Preto. Universidade de São Paulo, Ribeirão Preto, 2007.

FINE, C.; HAX A. A estratégia de Manufatura: uma metodologia e uma ilustração. In: TEIXEIRA, R.; LACERDA, D. P.; ANTUNES, J.;VEIT, D. (orgs.). Estratégia de Produção: 20 Artigos para aumentar a competitividade da empresa. São Paulo: Bookman, 2014. 
GIL, Antônio Carlos. Métodos e técnicas de Pesquisa Social. São Paulo: Atlas, 1999.

GOLDRATT, E. M. Corrente Crítica. São Paulo: Nobel, 1998.

Não é sorte: A aplicação dos processos de raciocínio da teoria das restrições. São Paulo: Nobel, 2004.

GOLDRATT, E.M.; COX, J. A Meta: Um processo de melhoria contínua. 2. ed. São Paulo: Nobel, 2002.

MARTINS, G. de A. Manual para elaboração de monografias e dissertações. São Paulo: Atlas, 2000.

PORTER, M. Estratégia Competitiva. Técnicas para análise de indústrias e da concorrência. Rio de Janeiro: Elsevier, 2004.

RENTES, A.F. TransMeth: Proposta de uma Metodologia para Condução de Processos de Transformação de Empresas. Tese de Livre-Docência. Escola de Engenharia de São Carlos, USP, 2000.

SLACK, N.; CHAMBERS, S.; JOHNSTON, R. Administração da Produção. 2. ed. São Paulo: Atlas, 2008.

WIMMER, Roger D.; DOMINICK, Joseph R. La investigación científica de los medios de comunicación: una introducción a sus métodos. Barcelona: Bosch, 1996.

WOMACK, J.; JONES, D. A Mentalidade Enxuta nas Empresas: elimine o desperdício e crie riqueza. Rio de Janeiro: Elsevier, 2004.

YIN, Robert K. Estudo de caso: planejamento e métodos. 2. ed. Porto Alegre: Bookman, 2001. 